\title{
3B Tasarımların Fiziksel Materyallerle Desteklenmesinin Akademik Başarı, Ders Tutum veMotivasyonuna Etkisi*
}

\author{
Ahmet Naci Çoklar ${ }^{1}$ (D) Esra Çekirge ${ }^{2}$ \\ Necmettin Erbakan Üniversitesi, Ahmet Keleşoğlu Eğitim Fakültesi, Bilgisayar ve Öğretim Teknolojileri Eğitimi Bölümü, \\ ahmetcoklar@hotmail.com (Sorumlu Yazar/Corresponding Author) \\ Necmettin Necmettin Erbakan Üniversitesi, Eğitim Bilimleri Enstitüsü, Bilgisayar ve Öğretim Teknolojileri Eğitimi Anabilim \\ Dalı, Meram, Konya, Türkiye, esraekti@gmail.com
}

\begin{tabular}{|c|c|}
\hline Makale Bilgileri & ÖZ \\
\hline $\begin{array}{l}\text { Makale Geçmişi } \\
\text { Geliş: 02.10.2020 } \\
\text { Kabul: 23.11.2020 } \\
\text { Yayın: 28.12.2020 } \\
\text { Anahtar Kelimeler: } \\
\text { 3B yazıcı, } \\
\text { Akademik başarı, } \\
\text { Motivasyon, } \\
\text { Tutum, } \\
\text { Tinkercad. }\end{array}$ & $\begin{array}{l}\text { Bu çalışmada 3B yazıcıları merkezine alarak 3B dijital materyallere ek olarak fiziksel materyal } \\
\text { kullanımının akademik başarı, ders tutum ve motivasyona etkisinin incelenmesi amaçlanmaktadır. } \\
\text { Araştırma } 2017-2018 \text { eğitim öğretim yılı birinci yarıyılda Konya ili Meram ilçesindeki bir } \\
\text { ortaokulda öğrenim gören } 7 \text {. sınıf toplam } 35 \text { öğrenci ile yürütülmüştür. Öğrenciler sadece 3B dijital } \\
\text { materyal kullanılan } 16 \text { öğrencinin yer aldığı kontrol grubu ve 3B dijital ve fiziksel materyal } \\
\text { kullanılan } 19 \text { öğrencinin yer aldığı deney grubu olmak üzere iki gruba ayrılmıştır. Uygulamada } \\
\text { deney ve kontrol grubunda işlenen ders kapsamında kendi tasarımlarını yaparak öğretmene } \\
\text { ulaştırmaları istenmiştir. Araştırma sonucunda dijital materyallere ek olarak fiziksel materyallerin bir } \\
\text { sonraki hafta öğrencilere gösterildiği grupta akademik başarının daha yüksek olduğu bulunmuştur. } \\
\text { Deney ve kontrol grubu öğrencileri arasında Teknoloji ve Tasarım dersine yönelik motivasyona göre } \\
\text { anlamlı bir fark bulunmamasına karşı; deney grubu öğrencilerinin derse yönelik tutumlarının } \\
\text { kontrol grubu öğrencilerine göre anlamlı ve olumlu bir fark olduğu sonucuna ulaşılmıştır. }\end{array}$ \\
\hline
\end{tabular}

\section{The Effect of Supporting 3D Designs with Physical Materials on Academic Achievement, Course Attitude and Motivation}

\begin{tabular}{|c|c|}
\hline Article Info & ABSTRACT \\
\hline $\begin{array}{l}\text { Article History } \\
\text { Received: } \mathbf{0 2 . 1 0 . 2 0 2 0} \\
\text { Accepted: } 23.11 .2020 \\
\text { Published: } 28.12 .2020 \\
\text { Keywords: } \\
\text { 3D printer, } \\
\text { Academic success, } \\
\text { Motivation, } \\
\text { Attitude, } \\
\text { Tinkercad. }\end{array}$ & $\begin{array}{l}\text { In this study, it is aimed to examine the effect of using physical materials in addition to 3D digital } \\
\text { materials on academic achievement, attitude and motivation by focusing on 3D printers. The } \\
\text { research was conducted with a total of thirty five } 7 \text { th grade students studying at a secondary school } \\
\text { in Konya province Meram district in the first semester of the } 2017-2018 \text { academic year. The students } \\
\text { were divided into two groups as the control group with } 16 \text { students using only 3D digital material } \\
\text { and the experimental group with } 19 \text { students using 3D digital and physical materials. In practice, } \\
\text { they were asked to make their own designs within the scope of the teacher in the experimental and } \\
\text { control groups and deliver them to the instructor. As a result of the research, it was found that the } \\
\text { academic success was higher in the group where physical materials were shown to the students in the } \\
\text { next week in addition to digital materials. Although there is no significant difference between the } \\
\text { experimental and control group students in terms of motivation for the Technology and Design } \\
\text { course; it was concluded that there is a significant and positive difference in the attitudes of the } \\
\text { experimental group students towards the course compared to the control group students. }\end{array}$ \\
\hline
\end{tabular}

Atıf/Citation: Çoklar, A. N. ve Çekirge, E. (2020). 3B Tasarımların Fiziksel Materyallerle Desteklenmesinin Akademik Başarı, Ders Tutum ve Motivasyonuna Etkisi, Ahmet Keleşoğlu Eğitim Fakültesi Dergisi, 2(2), 181-193.

\footnotetext{
* Bu çalışma Bilimsel Araştırma Projeleri (BAP) tarafından 181310002 nolu Yüksek Lisans tez projesi olarak desteklenmiş ve Esra ÇEKİRGE tarafından Prof. Dr. Ahmet Naci ÇOKLAR danışmanlığında yazılan yükssek lisans tez çalışmasının bir bölümünden üretilmiştir.
} 


\section{GİRIŞ}

Eğitim 4.0 içeriğinde öğrencilere yaratıcılık, eleştirel düşünme, yenilikçi düşünme gibi önemli becerileri kazandırmak amaçlanmaktadır. Geleceğin odak noktası teknolojiler kapsamında Endüstri 4.0'ın önemli bir bileşeni de eklemeli imalat (Additive Manufacturing)'tır. Eklemeli imalatın eğitim ortamlarında kullanımı konusunda giderek artan önem kazanan ve öğrencilerin 21. yy. becerilerini geliştirebilmeleri için kendi üretimlerini yapabilecekleri 3 boyutlu yazdırma teknolojileri önemli bir vizyona sahiptir.

1986 yılında Chuck Hull tarafindan icat edilen 3B bask1, dijital ortamdaki 3 boyutlu model dosyasını fiziksel bir nesneye dönüştürme işlemidir (Krassenstein, 2015). 3 boyutlu yazdırma inovasyon ve üretici sanayisindeki bir terimdir. "Eklemeli imalat (additive manufacturing)", "masaüstü üretim (desktop producing)", "hızlı prototipleme (rapid prototyping)", "dijital imalat (digital fabrication)" bu yeni teknoloji için farklı isimlerdir. Tamamen bilgisayarlı ürün tasarlama ve üretme işleminin bir sonucu olarak 3B bask1, dijital üretimdeki büyük gelişimin bir parçasıdır (Junte, 2017). 3 boyutlu yazıcılar 2006 yılında başlayan "İnsanlığın ilk genel amaçlı kendi kendini kopyalayan üretim makinesi” olarak kendini tanıtan RepRap projesi ile lüks seviyesinden birçok kimsenin rahatlıkla üretip kullanabileceği bir kullanım sahasına kavuşmuştur (Bowyer, 2014). Özellikle tıp sektöründe modelleme ve implatasyonda hatta ileriki aşamalarda organ nakillerinde, havacılık ve uzay sanayinde uçakların üretiminde, üretim tesislerinde hızlı ve daha uygun maliyetli prototiplemede, sanat ve eğitim alanında yaratıcılığ desteklemede, kitlesel bireyselleştirme (Mass customization) olarak adlandırılan ürünlerin kişiye özgü olarak tasarlanarak üretiminde kullanılmaktadır. 3B baskı dünyamızdaki hemen hemen her endüstri tarafında bir şekilde kendine yer bulmuştur (Bonfield, Salter, Longmuir, Benson ve Adachi, 2020). 3B yazıcıların kullanımı konusunda son dönemde eğitimin de önemli bir yer bulmaya başladığı söylenebilir.

Teknolojiyle bütünleşik öğrenci merkezli öğrenme ortamları, eleştirel düşünebilecek, problem çözebilecek, başkalarıyla iş birliği yapabilecek ve öğrenme sürecine derinden girebilecek öğrenciler yetiştirmeye yardımcı olmaktadır (Lacey, 2010). 3B yazıcılar, ileri teknoloji ürünü olan ve öğrenciyi öğrenme ortamında merkezine oturtan bir teknoloji ürünüdür. Eğitimi desteklemek için 3B yazıcı gibi dijital üretim teknolojilerinin kullanımı eskilere dayanmaktadır. Mimarlık ve mühendislik disiplinleri, hızlı prototipleme teknolojilerinin ilk uygulayıcılarındandır. 1997 yılında yapılan bir çalışmada hızlı prototiplemeyi mühendislik müfredatına entegre etmek için bir örnek olay çalışması yapılmıştır (Helge Bøhn, 1997). Teknolojinin giderek gelişmesi ile birlikte 3B yazıcıların da kullanım alanları ve erişilebilirlikleri artmış, maliyetleri de aynı oranda azalmıştır. Günümüzde açık kaynak kodlar (open source code), elektronik ve mekanik kitler ile çok küçük maliyetlere 3B yazıcıya sahip olunabilmektedir. Zhang, Anzalone, Faria ve Pearce (2013), bir fen laboratuvarının 3 boyutlu yazıcılar kullanılarak satın alma seçeneğinden çok daha düşük bir maliyetle kurulabileceğini belirtmişlerdir. Teknoloji maliyetindeki azalma, birçok okulun teknolojiyi müfredata uygulamasına izin verir ve daha fazla öğrenciye daha erişilebilir olmasını da sağlamaktadır (Hollenbeck \& Fey, 2009).

3B yazıcıların eğitimde kullanımına yönelik çalışmalar incelendiğinde Kuzu Demir ve arkadaşları (2016) tarafından yapılan, Türkiye'yi temel alan 3 boyutlu yazıcıların eğitim alanındaki incelemeleri kuramsal olarak bir temel oluşturmuştur ve genel durum değerlendirmesi niteliği taşımaktadır. Sezer ve Şahin (2016) 3B baskı üretiminin sağlık ve eğitimdeki kullanım alanlarını inceledikleri araştırmalarında özellikle zorlu anatomik ve patolojik koşullarda öğrenmeyi geliştirdiğini, uzmanlık eğitiminde yoğun bir eğitime izin verdiğini, yükseköğretimde proje tabanlı öğrenmede uygulanabilmesi açısından eğitime önemli katkılarının olduğunu saptamışlardır. Matematik disiplininin ele alındığı farklı bir çalışmada (Yılmaz \& Algil, 2018) matematik dersinde kullanılabilecek bir tangram tasarım ve üretim aşamaları gösterilmiş̧ir. Görsel ve zihinsel zekanın aynı anda kullanımının düşünce gücünü geliştirdiğine dayanarak 
geliştirilen materyal olan tangramın geometride öteleme, yansıma, dönme gibi konuların öğrenimine katkı sağladığı öne sürülmüştür. Kwon (2017) tarafından 2 haftalık STEM yaz kampında 47 ortaokul öğrencisiyle yapılan araştırmada, 3B tasarım ve baskının öğrencilerin motivasyon, ilgi alanı, matematik becerisi ve gerçek yaşam becerilerine olumlu bir etki yaptı̆̆ 1 sonucuna varılmıştır. Huleihil'in (2017) matematik öğretiminde 3B baskı etkisini ölçtüğü, yöntemi kontrol ile deney grubu arasındaki karşılaştırmaya dayanan araştırmada elde ettiği sonuçlar, 6. sınıf öğrencilerin matematiğe olan yansıtıcı düşünme yeteneklerinin anlamlı derecede arttığını göstermektedir. Senirkent Meslek Yüksekokulunda yapılan bir çalışmada (Özsoy, 2018) 3B yazıcı ile teknik tasarım ve imalatı yapılan gruptaki öğrencilerin 3B analitik düşünme ile zihinsel, mesleki ve toplumsal gelişimlerine katkı sağladığı gözlenmiştir. Togay, Güneş, Coşkun ve Gedik (2017), kurulan bir dijital fabrikasyon laboratuvarını kullanan öğrencilerle yaptıkları görüşmelerde; öğrencilerin geleneksel yöntemlere göre zamanı daha iyi planladıkları ve karar alma mekanizmalarında daha ayrıntılı düşündükleri, öğretmen öğrenci ilişkisinin geliştiği, öğrencilerin kendilerine olan öz saygısında bir artış meydana geldiği sonucuna ulaşmışlardır. Bir diğer çalışmada 3B baskının öğrenme üzerindeki etkisi, "Kalp, Akciğerler ve Kan” dersi sirasında 127 birinci sınıf tıp öğrencisinin test performanslarının analizi yoluyla araştırılmış, sonuca göre 3B baskılı modellerin kullanımı öğrenmeyi desteklemiş; 3B baskı kullanan deney grubundakiler için ortalama test puanları \%14,4 daha yüksek çıkmıştır (Smith, Tollemache, Covill \& Johnston, 2018). Başka bir çalışmada, 52 lisans tıp öğrencisi kardiyak anatomi öğreniminde kadavra materyallerin ve $3 \mathrm{~B}$ basılı modellerin kullanımını araştırmıştır. 52 öğrenciden 18'i yalnızca kadavra materyalleri, 16's1 sadece 3B basılı modelleri, 18'i ise iki tipin bir kombinasyonunu kullanmıştır. Test öncesi ve sonrası test puanlarının istatistiksel analizi, yalnızca 3B basılı modelleri kullanan grup için test sonrası puanların anlamlı derecede yüksek olduğunu göstermiştir (Helge Lim, Loo, Goldie, Adams \& McMenamin, 2016).

Yapılan araştırmalar incelendiğinde 3B yazıcının eğitime olumlu yönde önemli bir katkısının olduğu söylenebilir. Çalışmalarda 3B yazıcıların derslerdeki aktif kullanımının öğrencilerin yaparak yaşayarak, deneme yanılma yoluyla öğrenmesine katkı sağladığı, üretim sürecini yakından gözlemlemeye yardımcı olduğu vurgulanmaktadır. Araştırmalarda elde edilen sonuçlar genel olarak 3B yazıcının öğrencilerin derse olan ilgilerine ve motivasyonlarına olumlu yönde etki ettiği ve öğrencilerin akademik başarısını artırdığı yönündedir.

Son yıllarda ortaya çıkan ve üretim süreçlerine katk1 sağlayan bir kavram olarak 3B materyaller özellikle 3B yazıcıların ucuzlaması ve daha erişilebilir hale gelmesi ile daha çok önem kazanmıştır. Bu yönü ile 3B materyallerin dijital ekrandan farklı olarak dokunma, uzamsal algılama, üretim hazzı sağlama gibi birtakım katkılar sağladığı da bilinmektedir. Bu araştırmada henüz ortaokul düzeyindeki öğrencilerin dijital 3B materyallere ek olarak üretilen bu dijital materyallerin 3B yazıcı çıktılarının birlikte kullanımının akademik başarı, derse yönelik tutum ve motivasyonlarına etkisi ele alınmıştır. Bu kapsamda fiziksel olarak zenginleştirilen 3B materyal kullanımının etkisinin öğrenciler açısından incelenmesi problem durumunu oluşturmuştur.

\section{Araștırmanın Amacı}

$\mathrm{Bu}$ araştırmanın amacı teknoloji ve tasarım dersinde 3 boyutlu dijital materyaller ile bu materyale ek olarak fiziksel materyal (3 boyutlu yazıcı çıtısı) kullanımının öğrencilerin akademik başarısı, derse yönelik tutum ve motivasyonlarına etkisini incelemektir. Bu kapsamda aşağıdaki sorulara yanıtlar aranmıştır.

1) 3B fiziksel ürün kullanımı ögrencilerin akademik başarıları üzerinde anlamlı bir farka neden olmakta midır? 
2) 3B fiziksel ürün kullanımının öğrencilerin derse yönelik tutumları üzerinde anlamlı bir farka neden olmakta midir?

3) 3B fiziksel ürün kullanımı öğrencilerin derse yönelik motivasyonları üzerindeki etkisi farklılaşmakta mıdır?

\section{YÖNTEM}

Bu bölümde araştırmanın modeli, katılımcıları, uygulama süreci, veri toplama araçları ile verilerin analizi bilgilerine yer verilmiştir.

\section{Araştırma Modeli}

3B yazıcı kullanımının akademik başarı, tutum ve motivasyonlarına etkisinin araştırıldığı bu araştırma nicel yöntem ile desenlenmiştir. Farklı açılardan öğrencilere etkisinin araştırılması nedeniyle yarı-deneme modelindedir. Yarı-deneme modelleri, neden-sonuç ilişkilerini belirlemeye çalışmak amacıyla, doğrudan araştırmanın kontrolü altında gözlenmek istenen verilerin üretildiği araştırma modelleridir (Fraenkel, Wallen \& Hyun, 2012).

\section{Katılımcilar}

Araştırmanın katılımcılarını 2017-2018 eğitim öğretim yılında Konya ili Meram ilçesinde bilgisayar laboratuarı olan bir ortaokulda öğrenim gören öğrenciler oluşturmaktadır. Bilgisayar sınıfının bulunmas1; Teknoloji ve Tasarım dersinin uygulamayı yapmaya müsait olması; okul yönetimi ve Teknoloji ve Tasarım dersi öğretmenin uygulamaya gönüllü olması sebebiyle söz konusu okul seçilmiştir. Çalışma, Teknoloji ve Tasarım dersi öğretmeni ile istişare edilerek belirlenen zamanda 7. sınıf öğrencilerine uygulanmıştır. İlgili okulda Teknoloji ve Tasarım dersinin uygulamalı bir ders olması sebebiyle sınıf yarıya bölünmektedir. Ders öğretmeninin yönlendirmesi ile C ve D şubeler ile çalışılmıştır. Katılımcılar kontrol grubunda 16, deney grubunda 19 öğrenciden oluşmaktadır. 3 haftalık uygulama süresi boyunca deney grubundaki her öğrencinin 3B dijital modelini basılabilir kontrolü yaparak çıktısını almak zaman aldığından dolayı sınırlı sayıda öğrenci katılmıştır. Araştırma öncesinde uygulama için öğrenci ailelerinden izin alınmıştır.

\section{İşlem Basamakları}

Araştırma için düşünülen ders işleyişi daha önce uygulanmadığı için tasarlanan uygulamadaki eksiklikleri tespit etmek adına 2016-2017 eğitim öğretim y1lında bir pilot çalışma gerçekleştirilmiştir. Konya ili Meram ilçesindeki uygulamaya gönüllü izin veren bir özel okulda gerçekleştirilen pilot çalışmaya 32 7. sınıf öğrencisi (11 kız, 21 erkek) katılmıştır. 3 hafta olan pilot uygulama sonrası tespit edilen eksiklikler giderilmiştir. Pilot uygulama sırasında, dersin işleneceği bilgisayar laboratuarının teknik aksaklıklarının mutlaka giderilmesi; dersin anlatılması sırasında öğretmenin kullanacağı projeksiyon, akıllı tahta, öğretmen bilgisayarı gibi teknik araç ve gereçlerin öğrencilere uyumlu ve problemsiz olarak çalıştı̆̆ından emin olunması, öğrencilerin Tinkercad uygulamasına üye olurken ve kullanırken yaşadıkları problemlerin tespit edilmesi ve ders sırasında öğrenciler için oturma düzeninin iyileştirilmesi gereklilikleri gibi yaşanan deneyimler gerçek uygulamaya oldukça katkı sağlamıştır.

Üç hafta planlanan uygulama süreci öncesinde öğrencilerin alışmalarını sağlamak için 1 haftalık bir ön hazırlık süreci de gerçekleştirilmiş, bu hafta uygulama sürecinin dışında tutulmuştur. Araştırmanın uygulaması için Teknoloji ve Tasarım dersi seçilmiştir. Bunun nedeni Teknoloji ve Tasarım dersinin içerik olarak 3B tasarım anlatmaya en yakın ders olmasıdır. Araştırmanın esas uygulaması için okul aramalarında bilgisayar laboratuarı bulunması ve Teknoloji ve Tasarım dersinde müsait olması kriterlerine bakılmıştır. Uygulamanın zamanlaması için ders öğretmeni rehberliğinde Teknoloji ve Tasarım dersi ders planınde 3B tasarıma en yakın kazanımlara sahip ünite olan "Ürün Geliştirme” ünitesi 
seçilmiştir. Ürün geliştirme ünitesinin kazanımları da baz alınarak öğrencilerin günlük hayatta kullanabilecekleri nesneler tasarlatılmıştır. Uygulama haftalık 2 saat olan Teknoloji ve Tasarım dersinde bir ders saati uygulayarak anlatım, bir ders saati öğrenci uygulaması olarak gerçekleştirilmiştir. Öğrencilerden dersin işlenişinden sonra derste 3B tasarımı anlatılan nesneyi kendi yaratıcılıklarını da katarak tasarlamaları ve ödevi dijital olarak teslim etmeleri istenmiştir. Deney grubunda istenen ödevler bir sonraki hafta 3B yazıcı aracılığıyla çıktı alınmış, fiziksel materyal şeklinde öğrencilere dağıtılarak incelemeleri istenmiştir. Kontrol grubunda istenen ödevlerle ilgili herhangi bir işlem yapılmamış, 3B materyal dijital olarak incelenmiştir.

3B tasarım dersi uygulama sürecinde her iki gruba da araştırmacı tarafından aynı içerik ile anlatılmıştır. Sadece deney grubunde 3B yazıcıdan alınan çıktı materyaller ile derste tasarlanan ürünlerin dokunabilir hale gelmesi sağlanmıştır.

\section{Veri Toplama Araçları}

Araştırmada veri toplama aracı olarak demografik bilgilere ek olarak aşağıdaki ölçme araçlarından da yararlanılmıştır.

Öğrenci Projelerini Değerlendirme Rubriği: Araştırmada öğrencilerin geliştirdikleri dijital materyalleri değerlendirebilmek için bir rubrik geliştirilmiştir. Rubriğin geliştirilmesi sürecinde Sezer (2005) tarafından ifade edilen rubrik geliştirme süreçleri takip edilmiştir. Materyalin değerlendirilmesine yönelik geliştirilen rubrik uygun materyal seçimi, görsel uyum-çekiciliğin sağlanması, unsurların birbiri ile uyumu, tasarımın karmaşıklığı, bütünlüğün sağlanması, materyalin tamamlanma durumu ve materyal özgünlüğü olmak üzere toplam 7 kritere göre değerlendirilmiştir. Değerlendirme kriterlerinin belirlenmesinde bilgisayar öğretmeni, BÖTE alanında öğretim elemanı ve Teknoloji ve Tasarım dersi öğretmeni olmak üzere üç farklı alan uzmanının görüşü ve onayı alınmıştır.

Teknoloji ve Tasarım Dersine Yönelik Tutum Ölçeği: Öğrencilerin Teknoloji ve Tasarım (TT) dersine yönelik tutumlarını belirlemek için Nuhoğlu (2008) tarafından geliştirilen Fen ve Teknoloji Dersine Yönelik Tutum Ölçeği uyarlanarak kullanılmıştır. Bu ölçek 20 maddeden oluşmaktadır. İstanbul'da Üsküdar ilçesinde yer alan 3 farklı ilköğretim okulunun 6. 7. ve 8. sınıflarında öğrenim gören 422 öğrenciye uygulanarak analizleri yapılan tutum ölçeğinin güvenirlik katsayısı (Cronbach alfa) .8739’tir. Ölçeğin kullanımı için izin alınmıştır.

Teknoloji ve Tasarım Dersine Yönelik Motivasyon Ölçeği: Teknoloji ve Tasarım Dersine yönelik motivasyonu belirlemek için Yaman ve Dede (2005) tarafından geliştirilen Fen Öğrenmeye Yönelik Motivasyon Ölçeği kullanılmıştır. Bu ölçek 23 maddeden oluşmaktadır. Beş farklı ilköğretim okulunun 6. 7. ve 8 . sınıflarında öğrenim gören 421 öğrenciye uygulanarak analizleri yapılan motivasyon ölçeğinin güvenirlik katsayısı (Cronbach alfa) .80'dir. Ölçeğin kullanımı için izin alınmıştır.

\section{Verilerin Analizi}

Araştırmaya katılan öğrencilerin verileri bilgisayar ortamına aktarılmadan önce verilerin geçerliği kontrol edilmiştir. Verilerin bilgisayar ortamına aktarılmasında her biri üçlü likert maddeler şeklinde ifadelerden oluşan Teknoloji ve Tasarım dersine yönelik tutum ölçeği, Teknoloji ve Tasarım dersine yönelik motivasyon ölçeklerinin tamamı için "1- Katılmıyorum", "2-Fikrim Yok" ve "3- Katıllyorum" şeklinde bir puanlama yapılmıştır. Verilerin analizi için demografik bilgilerin yüzde ve frekans değerleri ile sunum yapılmıştır. Araştırma genelinde sayıların az olması, parametrik analiz ön şartının sağlanamaması nedeniyle parametrik olmayan testler ile analiz işlemi gerçekleştirilmiştir. Bu kapsamda deney ve kontrol grubundaki öğrencilerin uygulama öncesi ve sonrasında derse yönelik motivasyon ve tutum puanları ile uygulama sonrasındaki akademik başarı puanları arasındaki farklılıklar İlişkisiz 
Ölçümler İçin Mann Whitney U-testi ile analiz edilmiştir. Verilerin analizlerinde bir paket programından yararlanılmış, anlamlılık düzeyi .05 olarak alınmıştır.

\section{BULGULAR}

Araştırma sonuçlarından elde edilen bulgular başlıklar şeklinde verilmiştir.

\section{B Fiziksel Ürün Kullanımının Öğrencilerin Akademik Başarı Durumları Üzerindeki Etkisi}

Tercihe bağlı olmakla birlikte Yorumların bu bölümde değil Tartışma kısmında yapılması önerilmektedir Araştırmanın alt amaçları doğrultusunda öncelikli olarak sadece 3B dijital materyal geliştirilen kontrol grubu ile 3B dijital materyale ek olarak fiziksel ürünün öğrencilere sunulduğu deney grubundaki öğrencilerin akademik başarıları arasındaki etki araştırılmıştır. Bu amaçla her iki grubun dijital materyaller şeklinde gerçekleştirmiş olduğu materyallere ait rubrikler ile belirlenen ortalama puanlar karşılaştırılmıştır (Tablo 1).

Tablo 1. Eğitim Süreci Sonrasında Grupların Akademik Başarı Durumlarının Karşılaştırılması

\begin{tabular}{cccccc}
\hline Gruplar & $\mathbf{n}$ & Sira Ortalaması & Sira Toplamı & $\mathbf{U}$ & $\mathbf{p}$ \\
Deney Grubu & 19 & 21,84 & 415,00 & & \\
Kontrol Grubu & 16 & 13,44 & 215,00 & & $.015^{*}$ \\
\hline
\end{tabular}

$* \mathrm{p}<.05$

Tablo 1'de görüldüğü üzere, eğitim süreci sonrasında deney ve kontrol grubu öğrencilerinin Teknoloji ve Tasarım dersindeki akademik başarı düzeyleri yapılan Mann Whitney U-testi sonucuna göre farklılaşmaktadır [U=79.00; $\mathrm{p}<.05]$. Deney grubu öğrencilerinin derse yönelik akademik başarı sıra ortalama puanları (21.84) ile kontrol grubu öğrencilerinin derse yönelik akademik başarı sıra ortalama puanları (13.44) arasındaki fark istatistiki olarak anlamlıdır. Dijital materyallere ek olarak fiziksel materyallerin bir sonraki hafta öğrencilere gösterildiği gruplarda akademik başarının daha fazla olduğu ifade edilebilir. Bu sonuç, öğrencilerin tasarladıkları ürünlerin dokunulabilir, somut hale getirilmesinin daha başarılı çizimler yapmalarını sağladı ̆̆ şeklinde de yorumlanabilir.

\section{B Fiziksel Ürün Kullanımının Öğrencilerin Derse Yönelik Motivasyonları Üzerindeki Etkisi}

Araştırmada 3B dijital ortamların kullanılması için Teknoloji ve Tasarım dersinde uygulama gerçekleştirilmiştir. Bu kapsamda üç haftalık bir süreçte öğrencilere 3B materyal tasarımı konusunda eğitim verilmiş, eğitim öncesinde ve sonrasında öğrencilerin Teknoloji ve Tasarım dersine yönelik motivasyon düzeyleri incelenmiştir (Tablo 2).

Tablo 2. Grupların Eğitim Süreci Öncesinde Teknoloji Tasarım Ders Motivasyonlarının Karşılaş̧tırılması

\begin{tabular}{cccccc}
\hline Gruplar & $\mathbf{n}$ & Sira Ortalaması & Sira Toplamı & $\mathbf{U}$ & $\mathbf{p}$ \\
Deney Grubu & 19 & 19.42 & 369.00 & & \\
Kontrol Grubu & 16 & 16.31 & 261.00 & & .370 \\
\hline
\end{tabular}

$* \mathrm{p}<.05$

Tablo 2'de görüldüğü gibi deney ve kontrol grubu öğrencilerinin Teknoloji ve Tasarım dersine yönelik motivasyonları eğitim süreci öncesinde farklılaşmamaktadır [U=125.00; $p>.05]$. Bir başka ifade 
ile deney grubu öğrencilerinin derse yönelik motivasyon sıra ortalama puanları (19.42) ile kontrol grubu öğrencileri motivasyon sıra ortalama puanları (16.31) arasındaki fark istatistiki olarak anlamlı değildir. Eğitim süreci öncesinde bu konuda iki grup arasında bir farklılık bulunmamaktadır.

Eğitim süreci sona erdikten sonra deney ve kontrol gruplarına Teknoloji ve Tasarım dersine yönelik motivasyon düzeylerini belirlemek amacıyla aynı ölçek yeniden uygulanmıştır. Uygulama sonucunda kontrol ve deney grubu öğrencilerinin Teknoloji ve Tasarım dersine yönelik motivasyonları değerlendirilmiş ve analiz sonuçları Tablo 3'te verilmiştir.

Tablo 3. Ĕ̌itim Öncesi ve Sonrası Teknoloji Tasarım Dersi Motivasyonlarının Karşılaştırılması

\begin{tabular}{|c|c|c|c|c|c|c|}
\hline & Öntest-Sontest & $\mathbf{n}$ & Sira Ortalaması & Sira Toplamı & $\mathbf{z}$ & $\mathbf{p}$ \\
\hline \multirow{3}{*}{ 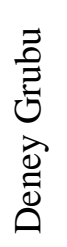 } & Negatif Sira & 6 & 5.17 & 31.00 & & \\
\hline & Pozitif Sira & 10 & 10.50 & 105.00 & -1.918 & .055 \\
\hline & Eşit & 3 & - & - & & \\
\hline \multirow{3}{*}{ 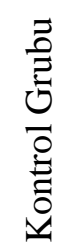 } & Negatif Sıra & 7 & 8.57 & 60.00 & & \\
\hline & Pozitif Sira & 9 & 8.44 & 76.00 & -.414 & .679 \\
\hline & Eşit & 0 & - & - & & \\
\hline
\end{tabular}

$* \mathrm{p}<.05$

Tablo 3 incelendiğinde deney grubu öğrencilerinin eğitim süreci öncesi ve sonrasında Teknoloji ve Tasarım dersine yönelik motivasyonları arasında anlamlı bir fark bulunmamaktadır $[\mathrm{z}=-1.918 ; \mathrm{p}>.05]$. Deney grubu öğrencilerinin eğitim sonrası derse yönelik motivasyonları ile eğitim öncesi motivasyonları arasında istatistiki açıdan anlamlı düzeyde bir farklılık bulunmamaktadır. Aynı şekilde kontrol grubu öğrencilerinin eğitim süreci öncesi ve sonrası Teknoloji ve Tasarım dersine yönelik motivasyonları arasında anlamlı bir bulunamamıştır [ $\mathrm{z}=-.414 ; \mathrm{p}>.05]$. Kontrol grubu öğrencilerinin de eğitim sonrasında motivasyon puanları eğitim öncesine oranla farklılaşmamaktadır. Bu açıdan verilen eğitimin gerek deney gerek kontrol grubu öğrencilerinin Teknoloji ve Tasarım dersine yönelik motivasyonları üzerinde anlamlı bir etkisi bulunamamıştır.

Diğer yandan 3B dijital materyaller ile hem 3B dijital materyal hem de bu materyallerin fiziksel çıktılarının kullanıldığı kontrol ve deney gruplarındaki öğrencilerinin Teknoloji ve Tasarım dersine yönelik motivasyonlarının farklılık düzeyini belirlemek amacıyla deney ve kontrol grubunun eğitim sonrası motivasyon puanları karşılaştırılmış ve analiz sonuçları Tablo 4'te verilmiştir.

Tablo 4. Eğitim Sonrasında Teknoloji ve Tasarım Dersine Yönelik Motivasyonların Karşılaştırılması

\begin{tabular}{cccccc}
\hline Gruplar & $\mathbf{n}$ & Sira Ortalaması & Sira Toplamı & $\mathbf{U}$ & $\mathbf{p}$ \\
Deney Grubu & 19 & 19.87 & 377.50 & & \\
Kontrol Grubu & 16 & 15.78 & 252.50 & & .239 \\
\hline
\end{tabular}

$* \mathrm{p}<.05$ 
Eğitim süreci sonrasında deney ve kontrol grubundaki öğrencilerin Teknoloji ve Tasarım dersine yönelik motivasyonları arasında anlamlı bir fark olmadığı Tablo 5'te görülmektedir [U=116,50; $\mathrm{p}>.05]$. Eğitim süreci sonrasında deney grubunun Teknoloji ve Tasarım dersine yönelik motivasyon sıra ortalama puanları (19.87) ile kontrol grubunun Teknoloji ve Tasarım dersine yönelik motivasyon sıra ortalama puanları (15.78) istatistiksel açıdan farklılaşmamaktadır. Bu açıdan üç haftalık bir eğitim süreci sonunda 3B dijital materyale ek olarak bu materyallerin 3B çıktılarının fiziksel olarak öğrencilere dağıtılmasının öğrencilerin ilgili derse yönelik motivasyonları üzerinde etkisi olmadığı söylenebilir.

\section{B Fiziksel Ürün Kullanımının Öğrencilerin Derse Yönelik Tutumları Üzerindeki Etkisi}

Araştırmada incelenen bir diğer alt amaç ise, 3B fiziksel materyal ile desteklenen eğitim sürecinin öğrencilerin Teknoloji ve Tasarım dersine yönelik tutum üzerindeki etkisi olmuştur. Bu kapsamda üç haftalık eğitim süreci öncesi ve sonrası öğrencilerin derse yönelik tutum puanları incelenmiştir. Tablo 5 'te öğrencilerin eğitim süreci öncesinde derse yönelik tutumlarından elde edilen analiz sonuçları verilmiştir.

Tablo 5. Grupların Eğitim Süreci Öncesinde Teknoloji Tasarım Dersi Tutumlarının Karşılaştırılması

\begin{tabular}{cccccc}
\hline Gruplar & n & Sira Ortalaması & Sira Toplamı & U & P \\
Deney Grubu & 19 & 18.37 & 349.00 & & \\
Kontrol Grubu & 16 & 17.56 & 281.00 & 145.00 & .816 \\
\hline
\end{tabular}

$* \mathrm{p}<.05$

Gerek deney ve gerek kontrol grubunda yer alan öğrencilerinin Teknoloji ve Tasarım dersine yönelik tutumlarının eğitim süreci öncesinde farklılaşmadığ 1 Tablo 5'ten görülmektedir [U=145.00; p>.05]. Bir başka ifade ile deney grubu öğrencilerinin derse yönelik tutum sira ortalama puanları (18.37) ile kontrol grubu öğrencileri tutum sıra ortalama puanları (17.56) arasında fark bulunmamaktadır. $\mathrm{Bu}$ sonuç eğitim süreci öncesinde her iki uygulama grubu için Teknoloji ve Tasarım dersine yönelik eşit düzeyde bir tutuma sahip olunduğunu göstermektedir.

Eğitim süreci sonrasında grupların derse yönelik tutumlarında farklılık meydana gelip gelmediğini belirlemek için grupların Teknoloji ve Tasarım dersine yönelik tutum puanları Wilcoxon İşaretli Sıralar Testi ile analiz edilmiştir (Tablo 6).

Tablo 6. Eğitim Süreci Öncesi ve Sonrası Tutumlarda Meydana Gelen Değişimin Karşılaştırılması

\begin{tabular}{|c|c|c|c|c|c|c|}
\hline & Öntest-Sontest & $\mathbf{n}$ & Sira Ortalaması & Sira Toplamı & $\mathbf{z}$ & $\mathbf{p}$ \\
\hline \multirow{3}{*}{ 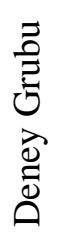 } & Negatif Sira & 5 & 5.60 & 28.00 & & \\
\hline & Pozitif Sira & 14 & 11.57 & 162.00 & -2.702 & $.007 *$ \\
\hline & Eşit & 0 & - & - & & \\
\hline \multirow{3}{*}{ 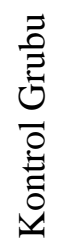 } & Negatif Sira & 6 & 7.33 & 44.00 & & \\
\hline & Pozitif Sıra & 10 & 9.20 & 92.00 & -1.242 & .214 \\
\hline & Eşit & 0 & - & - & & \\
\hline
\end{tabular}


$* \mathrm{p}<.05$

Tablo 6'dan görüleceği üzere, deney grubu öğrencilerinin eğitim süreci öncesi ve sonrasında Teknoloji ve Tasarım dersine yönelik tutum puanları arasında anlamlı bir fark meydana gelmiştir [z=2.702; $\mathrm{p}<.05]$. Bir başka ifade ile 3B dijital materyale ek olarak öğrencilerin yaptı̆̆ çizimlerin 3B fiziksel materyal halinin dağıtıldığı grupta öğrencilerin derse olan tutumlarının arttığı gözlenmiştir. Kontrol grubundaki öğrenciler için yapılan karşılaştırma test sonuçlarına göre eğitim süreci öncesi ve sonrası Teknoloji ve Tasarım dersine yönelik tutumları arasında farklılık olmadığı görülmüştür $\quad[\mathrm{z}=-1.242$; p>.05]. Sonuç olarak deney grubundaki öğrencilerin eğitim süreci sonrasında derse yönelik tutum puanları artarken, kontrol grubunda artış olmamıştır.

Son olarak deney ve kontrol gruplarının eğitim süreci sonrasında Teknoloji ve Tasarım dersine yönelik tutum puanları karşılaştırılmıştır (Tablo 7).

Tablo 7. Eğitim Süreci Sonrasında Gruplarının Teknoloji Tasarım Ders Tutumlarının Karşılaştırılması

\begin{tabular}{cccccc}
\hline Gruplar & n & Sira Ortalaması & Sira Toplamı & U & p \\
\hline Deney Grubu & 19 & 21.63 & 411.00 & & \\
Kontrol Grubu & 16 & 13.69 & 219.00 & 83.00 & $.022^{*}$ \\
\hline
\end{tabular}

$* \mathrm{p}<.05$

Tablo 7'de görüleceği üzere eğitim süreci sonrasında gruplar arasında Teknoloji ve Tasarım dersine yönelik tutum puanları açısından bir farklılık bulunmaktadır [U=83,00; $<<.05]$. Eğitim süreci sonrasında deney grubunun Teknoloji ve Tasarım dersine yönelik tutum sıra ortalama puanları (21.63) iken, kontrol grubunun Teknoloji ve Tasarım dersine yönelik tutum sıra ortalama puanları (13.69) farklılaşmaktadır. $\mathrm{Bu}$ açıdan 3B dijital materyale ek olarak 3B fiziksel materyal dağıtmak, sadece 3B dijital materyal kullanmaya oranla Teknoloji ve Tasarım dersine yönelik tutumu artırmada daha etkili olmuştur.

\section{SONUÇLAR VE TARTIŞMA}

Araştırma kapsamında 2017-2018 eğitim öğretim yılı birinci yarıyılda 3B dijital materyallerin 3B fiziksel materyaller ile desteklenmesinin öğrenciler üzerindeki etkisini belirlemek amaçlanmıştır. $\mathrm{Bu}$ kapsamda 3B dijital materyallerin kullanılabileceği bir eğitim ortamı planlanmıştır. Bu plan doğrultusunda Teknoloji ve Tasarım derslerinin bu amaca yönelik uygulamalar içerdiği görülmüş, bilgisayar laboratuarı olan ve bu konuda destek sunan bir okuldan izin alınmış, 3 haftalık bir eğitim süreci planlanmıştır. Ders kapsamında belirlenen içerik anlatılırken, her hafta sınıfta uygulamalar yaptırılmıştır. Deney ve kontrol grubunun her ikisinde de 3B dijital materyaller aynı şekilde uygulanırken, deney grubuna farklı olarak her öğrencinin yaptığı çalışma bir sonraki hafta 3B yazıcıdan alınan çıktısı şeklinde fiziksel materyal olarak getirilerek, dijital materyali ile birlikte gösterilmiştir. Araştırmada 3B fiziksel materyal ile desteklenen 3B fiziksel materyal tasarımını konu alan eğitim sürecinin öğrencilerin akademik başarı, Teknoloji ve Tasarım dersine yönelik tutumları ile motivasyonları üzerindeki etkisi araştırılmış, aşağıdaki sonuçlar elde edilmiştir.

Eğitim sürecinde öğrencilerin geliştirdikleri dijital materyallerinin fiziksel olarak sunulması öğrencilerin akademik başarısını artırmıştır. Öğrencilerin somut olarak yaptıkları dokunlabilir tasarımları görmeleri, onların tasarım yeterliklerini de artırmıştır. Bu sonuç, öğrencilerin tasarladıkları ürünlerin dokunulabilir ve somut hale getirilmesi daha başarılı çizimler yapmalarını sağladığı şeklinde düşünülmektedir. Alan yazında 3B baskının öğrencilerin akademik başarısı üzerine etkisini inceleyen araştırmalar mevcuttur. Philadelphia'daki bir kız lisesinde 10. sınıf kimya dersinde gerçekleştirilen 
çalışmada sonuç olarak 3B baskı kullanan öğrencilerin konuyu daha güçlü bir şekilde kavradığ bulunmuştur (Chery vd., 2015). 3B baskının öğrenme üzerindeki etkisinin tıp öğrencilerinin test performansıyla analiz edildiği araştırmalar da 3B baskı model kullanan öğrencilerin daha başarılı olduğunu göstermiştir (Smith vd., 2018; Lim vd., 2016). Bunların aksine Chien (2017) tarafindan yapılan öğrencilerin CO2 ile çalışan yarış arabaları tasarladıkları bir araştırmada 3B baskı ve manuel tasarım yapan öğrenciler arasındaki öğrenme performansında anlamlı bir fark bulunamamıştır.

Öte yandan doğrudan akademik başarıyı ölçmeyen fakat akademik başarıyı etkileyen bazı faktörleri inceleyen araştırmalar da mevcuttur. Kwon (2017) tarafindan ortaokul öğrencilerine yapılan araştırmada 3B yazıcıların matematik becerisine katkı sağladığı sonucuna varılmıştır. Huleihil'in (2017) matematik öğretiminde 3B baskı etkisi üzerine elde ettiği sonuçlar, öğrencilerin matematiğe olan yansıtıcı düşünme yeteneklerinin anlamlı derecede arttığını göstermektedir. Avustralyalı 2 ilkokul öğretmeninin yaptığı bir çalışmada, öğrencilerin sınıfta 3B tasarım ve baskı kullandıktan sonra şekilleri zihinsel olarak döndürme (mekânsal zekâ) ve manipüle etme yeteneklerinde önemli bir gelişme gösterdikleri sonucuna varılmıştır (Gordon \& Cowen, 2017). Öğrencilerin 3B bask1 alarak daha somut öğrenme gerçekleştirmesini teyit eden benzer araştırmalar vardır. Micallef (2015), 3B yazdırmanın soyut kavramları fiziksel nesneler haline getirerek eğitim ortamında daha anlamlı bir etki sağladığını belirtmiştir. Peels (2017) de 3 boyutlu yazdırmanın soyut kavramları somutlaştırarak derslerde daha fazla ilgi çekmek amacıyla kullanıldığını ifade etmiştir.

3B bask1 ile dokunulabilir bir nesne haline gelen öğrenme süreci farklı öğrenme stillerini de öğrenme ortamına dahil ettiğinden dolayı akademik başarıyı yükselttiği düşünülmektedir. Fiziksel dokunsallığ 1 ve yaratılan fiziksel eserlerin gözlenebilirliğini geliştirmenin yanı sıra, bağımsız ve içe dönük çalışma için kendi kendini yöneten yapı ve kapasiteye izin verir. Sanal materyallere göre 3B baskı eserlerin avantajının vurgulandığı bir araştırmada 3B baskının fiziksel dokunsallığın ve tasarlanan fiziksel eserlerin gözlenebilirliğinin iyileştirmesinin yanı sıra bağımsız ve içe dönük çalışmalar için kendi kendine yönetilebilen yapı ve kapasiteye izin verdiklerini belirtmiştir (Chen vd., 2017). Yapılan bir çalışmada, 3B yazıcı kullanımının farklı öğrenme stillerinin uygulanmasına olanak sağladığı, özellikle bazı öğrencilerin ilgisini çekmek için faydalı olduğu tespit edilmiştir (Kostakis vd., 2015). 3B yazdırma ile öğrenmenin farklı öğrenme stilleri ile ilişkisini inceleyen bir araştırmada kuramsal kavramları göstermek için 3B basılı eserlerin kullanılmasının tercih edilen aktif, refleksif, teorik ve pragmatik öğrenme stillerine göre farklı öğrenci gruplarını destekleyebileceği sonucuna ulaşılmıştır. Yüksek öğretimde uygulanan metodolojik çeşitlilik ne kadar yüksek olursa, çoğu öğrenci için öğrenme o kadar verimli olmaktadır. Ayrıca, öğrenciler çeşitli öğrenme stilleri ile desteklendiği için daha sorumlu, motive olmuş, dahil olmuş ve daha yüksek seviyeli öğrenme seviyelerine ulaştıkları için yeni bilgileri daha etkin bir şekilde özümseyebilmekte, uygulayabilmekte ve tanımlayabilmektedirler. Horowitz ve Schultz'a (2014) göre, eğitim sürecinde fiziksel modeller hem görme hem de dokunma ve ayrıntılı inceleme anlamında katk1 sağlayıcıdır.

Üç haftalık bir eğitim süreci sonunda 3B dijital materyale ek olarak bu materyallerin 3B çıktılarının fiziksel olarak öğrencilere dağıtılmasının öğrencilerin ilgili derse yönelik motivasyonları üzerinde etkisi olmadığı söylenebilir. Alan yazındaki bazı ilgili araştırmalar varılan sonucun aksine 3B yazıcının motive edici olduğunu söylemektedir. Kwon (2017) tarafından ortaokul öğrencileriyle yapılan araştırmada 3B yazıcıların öğrencilerin derse olan motivasyonuna olumlu bir etki yaptığı sonucuna varılmıştır. Politecnico di Torino'da Makine Mühendisliği Yüksek Lisansı sırasında 3B baskıyı proje öğrenme ortamına dahil etmenin öğrenci motivasyonu, anlayışı, ilgisi ve eğitimi ile ilgili olarak öğrencilere olumlu geri bildirim sağladığı bulunmuştur (Minetola, Iuliano, Bassoli \& Gatto, 2015). Hong Kong Şehir Üniversitesinde mühendislik temelli genel eğitim kursuna 3B yazıcı öğretiminin tanıtılması için yedi aşamalı bir pedagojik model ile öğrencilerin öğrenme görevinin, yenilikçi fikirlerinin gelişimini 
desteklediğini ve öğrenme motivasyonlarını arttırdığını bildirmişlerdir (Chiu vd., 2015). Araştırma sonucu elde edilen bulgunun fiziksel materyal karşılaştırması sebebiyle anlamlı bir farklılık oluşturmadığı düşünülmektedir. Nitekim alan yazında 3B tasarımın öğrencilerin derse yönelik motivasyonunu artırdığına yönelik araştırmalar da mevcuttur. Tu ve Chiang (2016) 3B tasarım eğitiminin öğrencilerin öğrenme güçlüklerini azalttığını ve motivasyonlarını artırdığını bulmuştur. Diğer yandan üç haftalık bir deneme sürecinin süre kısıtlaması nedeniyle motivasyonları etkilememiş olabilir. Daha uzun dönemli çalışmalar yapılması, motivasyona yönelik sonuçların farklılaşmasını sağlayabilir.

3B dijital materyale ek olarak 3B fiziksel materyal dağıtmak, sadece 3B dijital materyal kullanmaya oranla Teknoloji ve Tasarım dersine yönelik tutumu artırmada daha etkili olmuştur. 3B baskının farklı öğrenme stillerine destek vermesi sebebiyle derse yönelik tutumu olumlu yönde etkilediği düşünülmektedir. Minetola vd. (2015) tarafından yapılan araştırmada 3B baskıyı öğrenme ortamına dahil etmenin makine mühendisliğine yönelik öğrenci tutumlarını geliştirdiği tespit edilmiştir.

3B tasarım eğitimi sırasında öğrencilerin yaptıkları çalışmalarda bazı öğrencilerin tek seferde başarılı bir sonuca ulaşamadığı görülmüştür. Ayrıca istenilenin dışına çıkarak yaratıcılıklarını kullanan öğrencilerin yaptıkları modellerin basılabilir hale getirilmesi için ufak müdahalelere ihtiyaç duyulduğu tespit edilmiştir. Bunların dışında bazı öğrencilerin bazı uygulama adımlarında teknolojiyi kullanma konusunda yardıma ihtiyaç duyduğu gözlenmiştir. Eğitim süreci içerisinde yaşanılan bu gibi birtakım engeller alanyazında da yer bulmuştur. Nemorin \& Selwyn (2017) 3B yazdırma odaklı bir tasarım projesinin uzun süren öğrenme aşamalarında ortaya çıkabilecek "hayal kırıklığı, fiziksel yorgunluk, zihinsel yorgunluk, bezginlik ve ara sıra panik" konusunda uyarmıştır. Ayrıca öğrenci teknolojik okuryazarlı̆̆ 1 ve yeni teknolojilere yönelik tutumlar, maliyetler ve müfredat ve öğretim standartlarına entegrasyon da zorluklar arasında sıralanmıştır (Bull vd., 2015).

\section{ÖNERILER}

Araştırmadan elde edilen sonuçlar doğrultusunda öğrenci sayısı artırılarak daha uzun dönemli çalışmaların yapılması, motivasyonu artıracağı düşüncesi ile bizzat öğrencilerin kendi materyallerini yazdıracakları çalışmaların desenlenmesi ve 3B yazıcıların farklı disiplinler ile birlikte kullanımı konusunda araştırmalar yapılması önerilebilir. Uygulamaya dönük ise 3B yazıcıların katkıları dikkate alınarak, okullarda kullanımının yaygınlaştırılması, bu konuda öğretmen eğitimlerinin düzenlenmesi önerilebilir.

\section{KAYNAKÇA}

Bonfield, C. A., Salter, M., Longmuir, A., Benson, M., \& Adachi, C. (2020). Transformation or evolution?: Education 4.0, teaching and learning in the digital age. Higher Education Pedagogies, 5(1), 223-246.

Bowyer, A. (2014). 3D printing and humanity's first imperfect replicator. $3 D$ printing and additive manufacturing, 1(1), 4-5.

Bull, G., Haj-Hariri, H., Atkins, R., \& Moran, P. (2015). An educational framework for digital manufacturing in schools. 3D Printing and Additive Manufacturing, 2(2), 42-49.

Chen, M., Zhang, Y., \& Zhang, Y. (2014). Effects of a 3D printing course on mental rotation ability among 10-year-old primary students. International Journal of Psychophysiology, 2(94), 240.

Chery, D., Mburu, S., Ward, J., \& Fontecchio, A. (2015, October). Integration of the Arts and Technology in GK-12 Science Courses. In 2015 IEEE Frontiers in Education Conference (FIE)(pp. 1-4). IEEE.

Chien, Y. H. (2017). Developing a pre-engineering curriculum for 3D printing skills for high school technology education. Eurasia Journal of Mathematics, Science and Technology Education, 13(7), 2941-2958.

Dede, Y., \& Yaman, S. (2008). Fen Öğrenmeye Yönelik Motivasyon Ölçeği: Geçerlik ve Güvenirlik Çalışması. Necatibey Eğitim Fakültesi Elektronik Fen ve Matematik Eğitimi Dergisi, 2(1), 19-37.

Fraenkel, J. R., Wallen, N. E., \& Hyun, H. H. (2012). How to design and evaluate research in education (Eight Edition). New York: McGraw-Hill. 
Gordon, G. \& Cowen, R. (2017). Why spatial intelligence is important and how to help develop it with 3d printing. 27 Mayıs 2019 tarihinde https://www.makersempire.com/spatial-intelligence-important-help-studentsdevelop-3d-printing/ adresinden erişilmiştir.

Helge Bøhn, J. (1997). Integrating rapid prototyping into the engineering curriculum-a case study. Rapid Prototyping Journal, 3(1), 32-37.

Helge Lim, K. H. A., Loo, Z. Y., Goldie, S. J., Adams, J. W., \& McMenamin, P. G. (2016). Use of 3D printed models in medical education: A randomized control trial comparing 3D prints versus cadaveric materials for learning external cardiac anatomy. Anatomical sciences education, 9(3), 213-221.

Hollenbeck, R., \& Fey, J. (2009). Contemporary curriculum issues: Technology and Mathematics in the Middle Grades. Mathematics Teaching in the Middle School, 14(7), 430-435.

Horowitz, S. S., \& Schultz, P. H. (2014). Printing space: Using 3D printing of digital terrain models in geosciences education and research. Journal of Geoscience Education, 62(1), 138-145.

Huleihil, M. (2017). 3D printing technology as innovative tool for math and geometry teaching applications. In IOP Conference Series: Materials Science and Engineering (Vol. 164, No. 1, p. 012023). IOP Publishing.

Junte, J. (2017). 3D Printing And Additive Manufacturing - The Implications For OSH. European Agency for Safety and Health at Work Discussion Paper. 10 Mayıs 2019 tarihinde https://osha.europa.eu/en/tools-andpublications/publications/3d-printing-new-industrial-revolution/view adresinden alınmıştır.

Kostakis, V., Niaros, V., \& Giotitsas, C. (2015). Open source 3D printing as a means of learning: An educational experiment in two high schools in Greece. Telematics and informatics, 32(1), 118-128.

Krassenstein, B. (2015). What is 3D Printing \& How Do 3D Printers Work? - A Guide. 10 Mayıs 2019 tarihinde https://3dprint.com/82272/what-3d-printing-works/ adresinden alınmıştır.

Kuzu Demir, E. B., Çaka, C., Tuğtekin, U., Demir, K., İslamoğlu, H., Kuzu, A. (2016). Üç Boyutlu Yazdırma Teknolojilerinin Eğitim Alanında Kullanımı: Türkiye'deki Uygulamalar. Ege Eğitim Dergisi, 17 (2), $481-503$.

Kwon, H. (2017). Effects of 3D Printing and Design Software on Students' Overall Performance. Journal of STEM Education: Innovations and Research, 18(4), 37-42.

Lacey, G. (2010). 3D printing brings designs to life. Tech Directions, 70(2), 17-26.

Minetola, P., Iuliano, L., Bassoli, E., \& Gatto, A. (2015). Impact of additive manufacturing on engineering education-evidence from Italy. Rapid Prototyping Journal, 21(5), 535-555

Nemorin, S., \& Selwyn, N. (2017). Making the best of it? Exploring the realities of 3D printing in school. Research Papers in Education, 32(5), 578-595.

Nuhoğlu, H. (2008). İlköğretim Fen ve Teknoloji Dersine Yönelik Bir Tutum Ölçeğinin Geliştirilmesi. Ilkogretim Online, 7(3), 627-639.

Özsoy, K. (2018). Üç Boyutlu (3B) Yazıcı Teknolojisinin Eğitimde Uygulanabilirliği: Senirkent MYO Örneği. Düzce Üniversitesi Bilim ve Teknoloji Dergisi, 7(2), 111-123.

Peels, J. (2017). 3D printing in education: How can 3D printing help students?. 23 May1s 2019 tarihinde https://3dprint.com/165585/3d-printing-in-education/ adresinden erişilmiştir.

Sezer, H., \& Şahin H. (2016). 3D Bask1 Materyalinin Eğitimde Kullanımı: QUA VADIS?. Tıp Eğitimi Dünyası, 15(46), 5-13.

Sezer, S. (2005). Öğrencinin akademik başarısının belirlenmesinde tamamlayıcı değerlendirme aracı olarak rubrik kullanımı üzerinde bir araştırma. Pamukkale Üniversitesi Eğitim Fakültesi Dergisi, 18(18), 61-69.

Smith, C. F., Tollemache, N., Covill, D., \& Johnston, M. (2018). Take away body parts! An investigation into the use of 3D-printed anatomical models in undergraduate anatomy education. Anatomical sciences education, $11(1), 44-53$.

Togay, A., Güneş, S., Coşkun, M., \& Gedik, E. (2017). The case of digital design and fabrication lab in product design education; Gazi Dlab.

Tu, J. C., \& Chiang, Y. H. (2016). The Influence of Design Strategy of Peer Learning on 3-D Software Learning. Eurasia Journal of Mathematics, Science \& Technology Education, 12(5), 1263-1271.

Yılmaz, M., \& Algil, M. (2018). Matematik Öğretim Materyallerinin 3d Yazıcılarla Üretimi ve Eğitimciye Sağladığı Katkılar. Journal of Awareness, 3(4), 41-52.

Zhang, C., Anzalone, N. C., Faria, R. P., \& Pearce, J. M. (2013). Open-source 3D-printable optics equipment. PloS One, 8(3), 1-13. 


\section{EXTENDED SUMMARY}

In order to have a say in the technology of the future, our students need to be qualified with 21 st century skills. The people who produce innovative solutions from a critical point of view via recognizing the problems in human life and can turn the solutions into products cooperatively will build the future. 3D printer which is one of the most popular technologies of the 4th Industrial Revolution and also a kind of additive manufacturing technologies, is an important educational technology that is able to upskill the students with 21 st century skills. In this study, it is aimed to examine the effect of $3 \mathrm{~d}$ printer usage on academic success, attitude and motivations.

It is in a semi-experimental model due to the investigation of the effects of using 3D materials on students from different angles. The participants of the study consist of $7^{\text {th }}$ grade students studying at a primary school with a computer laboratory in Konya province Meram district in the 2017-2018 academic years. Participants consist of 16 students in the control group and 19 students in the experimental group. During the 3-week practice period, a limited number of students (30) participated in the experiment. During the research term of the 3D design lesson, the experimental and control groups were explained by the researcher with the same content for 3 weeks and two hours a week. Only the output materials taken from the 3D printer in the experimental group and the products designed in the lesson were made wearable. Due to the low numbers in the research and the lack of the prerequisite for parametric analysis, the analysis process was carried out with nonparametric tests.

As a result of the research, the following findings were obtained. In addition to digital materials, it can be stated that the academic success is higher in groups where physical materials are shown to students the next week. At the end of a three-week education period, in addition to 3D digital material, physically distributing the 3D printouts of these materials to the students has no effect on the motivation of the students for the relevant course. Finally, distributing 3D physical material in addition to 3D digital material increased students' attitude towards Technology and Design course.

Presenting the digital materials developed by the students physically during the education process increased the academic success of the students. The fact that students see the tangible designs they have made has increased their design competencies. This result is thought to be that making the products designed by the students tangible and concrete enables them to make more successful drawings. At the end of a three-week education process, it can be said that in addition to the 3D digital material, physically distributing the $3 \mathrm{D}$ outputs of these materials to the students does not have an effect on the motivation of the students for the relevant course. On the other hand, a threeweek trial period may not have affected motivations due to the time limitation. Conducting longer-term studies can differentiate motivational results. Distributing 3D physical material in addition to 3D digital material has been more effective in increasing the attitude towards Technology and Design lesson than using only 3D digital material. It is thought that 3D printing has a positive effect on the attitude towards the lesson as it supports different learning styles.

In line with the results obtained from the research, it can be suggested to make longer-term studies by increasing the number of students, to design the works that students will personally print their own materials with the thought that it will increase motivation, and to conduct researches on the use of 3D printers with different disciplines. Considering the contributions of 3D printers in practice, it can be suggested to expand their use in schools and to organize teacher training on this subject. 